\title{
Rancang Bangun Alat Bantu Physiotherapy Penggerak Lengan Manusia untuk Penderita Lumpuh Parsial Sementara Berbasis Voice Command Android
}

\author{
Asih Setiarini $^{1}$, Hanifah Nur Kumala Ningrum ${ }^{2}$, Mohammad Luqman $^{3}$, Rikky Yana Okananda ${ }^{4}$ \\ 1,2,3,4 Politeknik Negeri Madiun \\ 1,2,3,4Jalan Serayu no. 84, Madiun, Telp.0351-452970 Fax 0351492960 \\ e-mail: ${ }^{1}$ asih_setiarini@pnm.ac.id, ${ }^{2}$ hanifah_nkn@pnm.ac.id
}

\begin{abstract}
Abstrak - Lumpuh adalah kondisi dimana gerak suatu bagian badan terganggu hingga tidak mampu bergerak sama sekali. Penyakit atau kondisi ini biasanya terjadi pada bagian ekstremitas seperti pada tangan dan kaki. Kelumpuhan yang sering terjadi adalah masalah perlukaan pada pembuluh dalam otak yang akan mengganggu syaraf motorik di sebagian tubuh maupun seluruh tubuh. Penelitian ini membahas tentang lengan bantu berbasis voice command android yang digunakan sebagai media terapi untuk penderita lumpuh. Voice command pada smartphone android yang diucapkan oleh pengguna akan diolah menjadi pergerakan dari lengan bantu yang kemudian dikirim menggunakan serial communication ke mikrokontroller Arduino sebagai pusat pengaturan. Pergerakan dari lengan bantu menggunakan PWM (Pulse Wide Modulation). Penggunaan PWM bertujuan untuk mengatur kecepatan pergerakan dari lengan bantu sesuai berdasarkan keluran sensor MPX5050DP yang terbaca sebagai kekuatan otot. Alat ini telah berhasil diujikan dengan menghasilkan parameter pergerakan lengan bantu yaitu sudut 130 derajat pada posisi angkat dan 30 derajat saat posisi turun.
\end{abstract}

Kata kunci: Voice command, Bluetooth, MPX5050DP, Arduino

\section{Pendahuluan}

Kelumpuhan adalah suatu kondisi dimana seseorang tidak mampu menggerakkan tubuh atau anggota gerak tubuhnya dikarenakan hilangnya fungsi otot pada orang tersebut. Salah satu cara penyembuhan kelumpuhan adalah fisioterapi yaitu dengan mengerakkan bagian yang diindikasikan mengalami kelumpuhan pada sudut-sudut tertentu [1].

Penelitian ini menggabungkan antara bidang kesehatan, teknologi digital dan elektronika yang diinteregasikan untuk menjadi sebuah perangkat yang dapat digunakan sebagai media fisioterapi kelumpuhan [2]-[4]. Perangkat ini sebagai lengan bantu yang dikendalikan menggunakan voice command atau perintah suara pada smartphone android. Perintah suara yang diucapkan oleh pengguna diolah oleh smartphone android, kemudian dikirim melalui wireless network via bluetooth ke arduino sebagai pengolah utama data.

Tujuan dari pembuatan lengan bantu adalah agar pasien penderita kelumpuhan dapat melakukan fisioterapi secara mandiri. Penelitian ini bertujuan untuk membuat lengan bantu yang dapat digunakan untuk fisioterapi agar kondisi pasien dapat kembali seoptimal mungkin. 


\section{Metode Riset}

\subsection{Sistem Gerak Lengan}

Pergerakkan dari lengan bantu ini berdasarkan dari voice command atau perintah suara yang diucapkan oleh pengguna. Perintah suara yang diinisialisasikan sebagai pergerakan dari lengan bantu yaitu angkat, turun, gerakkan, berhenti dan skala. Perintah skala digunakan untuk mengetahui skala kekuatan otot dari pengukuran sensor. Media untuk mengucapkan perintah adalah aplikasi pada smartphone android. Mengacu dari fisioterapi dalam ilmu kesehatan, pergerakkan fisioterapi pada kelumpuhan di bagian lengan dijelaskan dalam Tabel 1[2].

Tabel 1. Rentang sudut pergerakan fisioterapi lengan

\begin{tabular}{|c|c|c|}
\hline Gerakkan & $\begin{array}{l}\text { Penjelasan } \\
\end{array}$ & Rentang \\
\hline Fleksi & $\begin{array}{l}\text { Menggerakkan siku sehingga } \\
\text { pergelangan tangan sejajar } \\
\text { bahu }\end{array}$ & Rentang 130 derajat \\
\hline Ekstensi & $\begin{array}{lll}\text { Meluruskan } & \text { siku } & \text { dengan } \\
\text { menurunkan } & & \\
\text { Tangan } & & \\
\end{array}$ & Rentang 30 derajat \\
\hline
\end{tabular}

Dari data acuan tersebut, maka diperoleh nilai rentang sudut pergerakan untuk lengan bantu. Tabel 2 menunjukkan perintah suara dengan rentang sudut pergerakan dari lengan bantu.

Tabel 2. Perintah suara dengan pergerakan lengan bantu

\begin{tabular}{ccl}
\hline Perintah & Sudut & \multicolumn{1}{c}{ Pergerakkan } \\
\hline Angkat & $130^{\circ}$ & Lengan terangkat hingga sejajar bahu \\
\hline Turun & $30^{\circ}$ & Lengan turun hingga persendian lurus \\
\hline Gerakkan & $30^{\circ}-130^{\circ}$ & $\begin{array}{l}\text { Kombinasi angkat dan turun dalam rentang 3 } \\
\text { kali gerakan }\end{array}$ \\
\hline
\end{tabular}

Pembacaan posisi sudut menggunakan sensor rotary encoder dan sebagai pengaman terdapat sensor limit switch untuk membatasi pergerakan dari lengan bantu apabila terjadi error pada rotary encoder. Pergerakan dari lengan bantu menggunakan aktuator berupa motor DC. Kecepatan dan kekuatan pergerakan dari motor DC berdasarkan nilai PWM atau Pulse Wide Modulation. Tabel 3 menunjukkan perbandingan nilai PWM dengan kecepatan pergerakan lengan dengan beban.

Tabel 3. Nilai PWM dengan waktu respon gerakan
\begin{tabular}{lcl}
\hline PWM & Waktu & \multicolumn{1}{c}{ Keterangan } \\
\hline 140 & - & Tidak bergerak \\
\hline 150 & 5 detik & Bergerak \\
\hline 160 & 3 detik & Bergerak \\
\hline
\end{tabular}

Aspek sistem kerja lengan bantu berdasarkan voice command, posisi sudut rotary encoder, dan nilai PWM. Gambar 1 menunjukkan sistem kerja dari lengan bantu. 

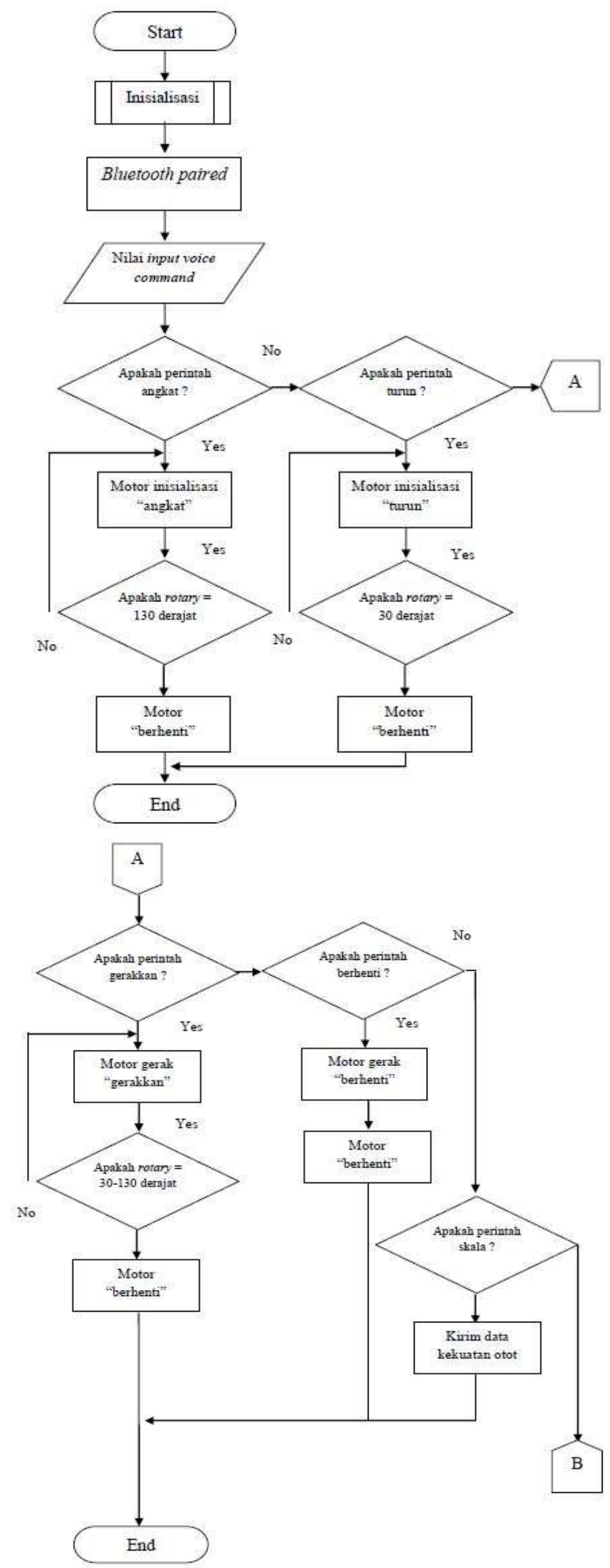


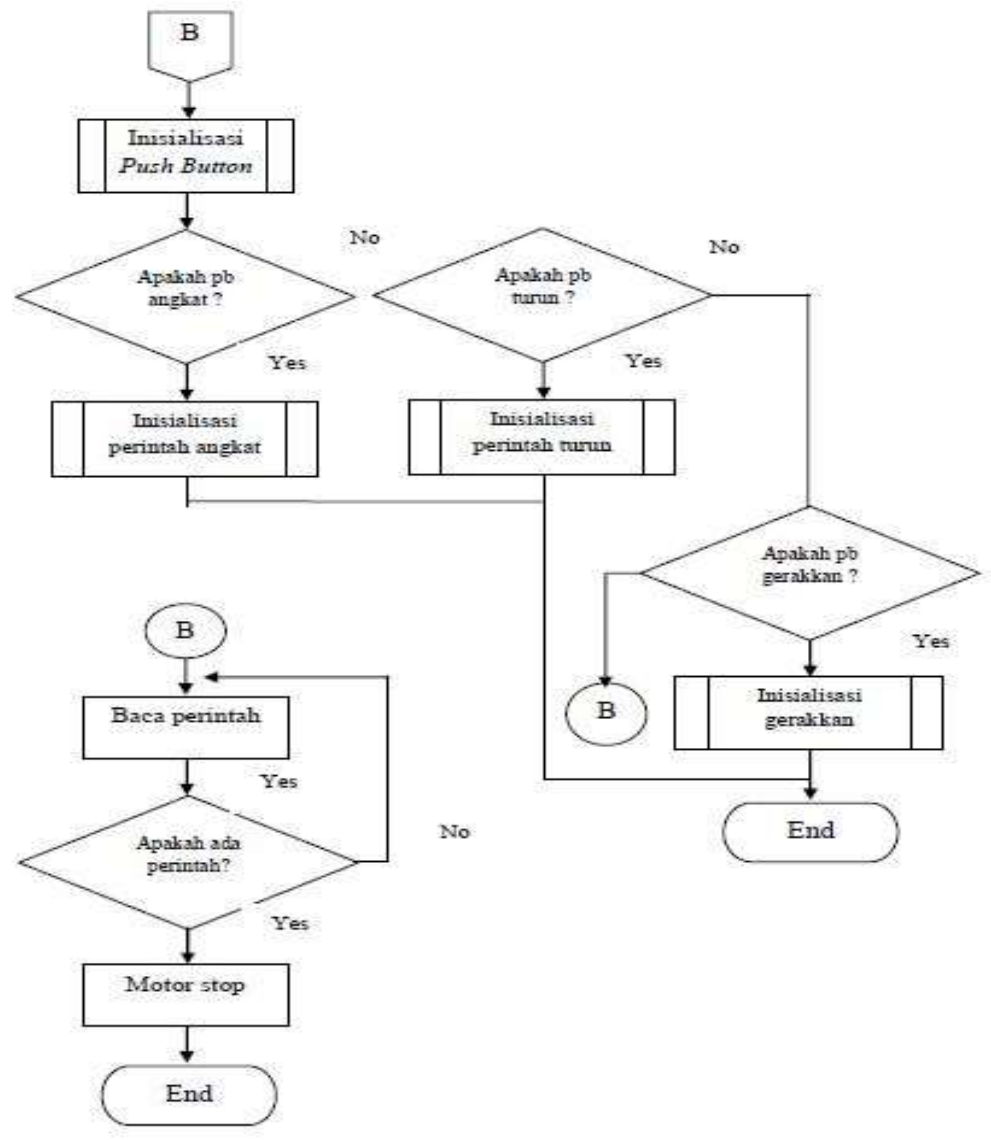

Gambar 1. Diagram alir sistem kerja

\subsection{Perhitungan Skala Kekuatan Otot}

Dalam Alat Bantu Penggerak Lengan Untuk Penderita Lumpuh Berbasis Voice Command Android terdapat penghitungan skala kekuatan otot. Skala kekuatan otot dikategorikan mulai skala 1 hingga 5. Perhitungan skala kekuatan otot berdasarkan nilai keluaran dari sensor MPX5050DP [3], dimana sensor ini mendapatkan masukan berupa tekanan udara yang bersumber pada manset yang dipasangkan pada lengan pengguna. Kontraksi dari otot bisep dan trisep akan mempengaruhi tekanan pada manset yang kemudian dikonversi menjadi kekuatan otot. Gambar 2 menunjukkan proses pengambilan data keluaran sensor MPX5050DP pada orang normal.

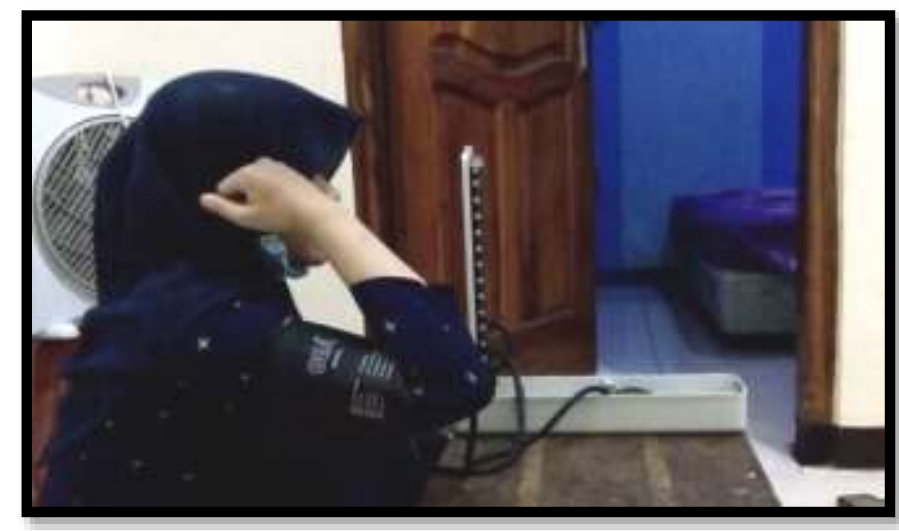

Gambar 2. Pengambilan data keluaran sensor MPX5050DP pada orang normal 
Gambar 3. menunjukkan proses pengambilan data keluaran sensor MPX5050DP pada penderita lumpuh.

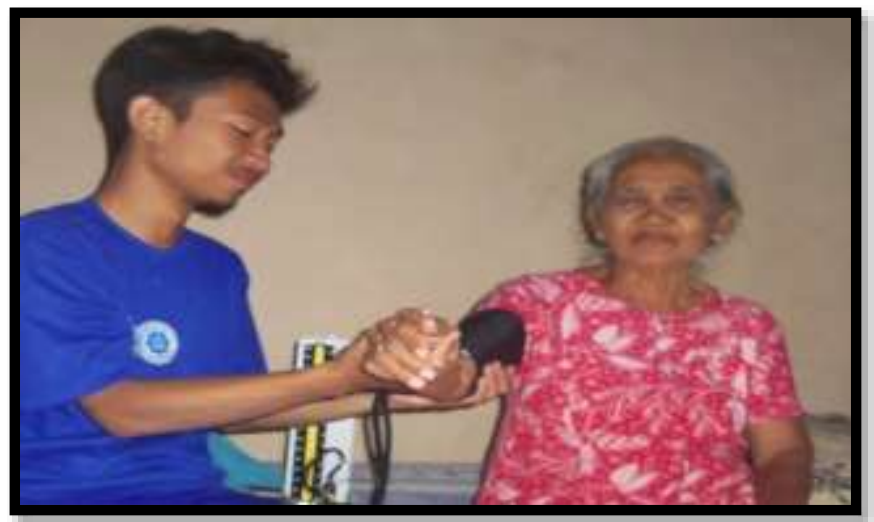

Gambar 3.Pengambilan data keluaran sensor MPX5050DP pada penderita lumpuh

Setelah melakukan pengambilan data maka akan diketahui nilai keluaran sensor MPX5050DP yang akan dikonversikan menjadi skala kekuatan otot[4]. Data keluaran sensor berdasarkan nilai keluaran tegangan (voltase) dari orang nomal dan penderita lumpuh. Tabel 4 menunjukkan nilai keluaran sensor MPX5050DP.

Tabel 4. Keluaran sensor MPX5050DP

\begin{tabular}{lll}
\hline Gerakan & Normal & Lumpuh \\
\hline Angkat & $3.79 \mathrm{~V}$ & $1,45 \mathrm{~V}$ \\
\hline Turun & $2.51 \mathrm{~V}$ & $2.51 \mathrm{~V}$ \\
\hline Gerakkan & $4.70 \mathrm{~V}$ & $2.59 \mathrm{~V}$ \\
\hline
\end{tabular}

Keluaran sensor MPX5050DP dari hasil gerakan angkat, turun dan gerakkan ini kemudian dikonversikan menjadi skala kekuatan otot dalam range skala 1-5. Tabel 5 menunjukkan nilai keluaran sensor MPX5050DP yang telah dikonversikan menjadi skala kekuatan otot.

Tabel 5. Nilai skala kekuatan otot

\begin{tabular}{lcc}
\hline \multicolumn{1}{c}{ Gerakan } & Orang Normal & Orang Lumpuh \\
\hline Angkat & 4 & 2 \\
\hline Turun & 3 & 3 \\
\hline Gerakkan & 5 & 3 \\
\hline
\end{tabular}

Nilai skala kekuatan otot yang telah dikonversikan kemudian dibandingkan dengan pengukuran skala kekuatan otot oleh praktisi kesehatan. Dimana nilai pengukuran sensor berbeda saat posisi turun baik pada orang normal maupun penderita lumpuh. Hal tersebut dikarenakan pengukuran dari pihak medis dilakukan secara menyeluruh pada otot pasien, berbeda dengan sensor yang hanya mengukur berdasarkan kontraksi otot.

\subsection{Pengiriman Data}

Pengiriman data meliputi komunikasi dua arah antara smartphone dengan arduino menggunakan wireless network via bluetooth. Gambar 4 menunjukkan proses komunikasi dari smartphone dengan arduino. 


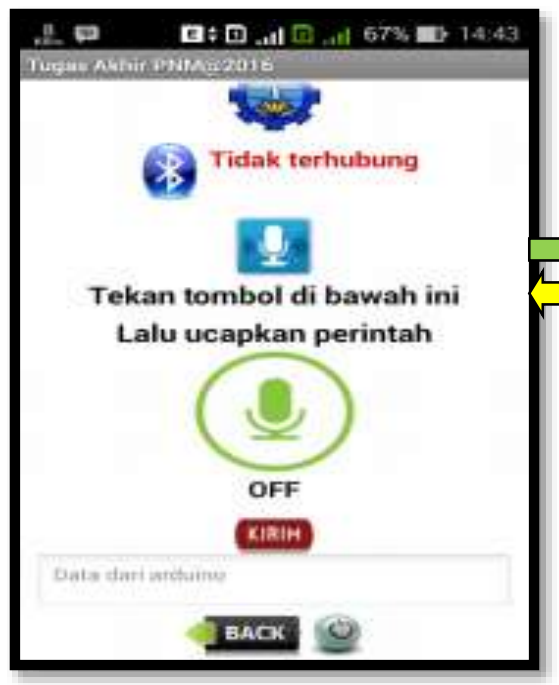

Aplikasi lengan bantu

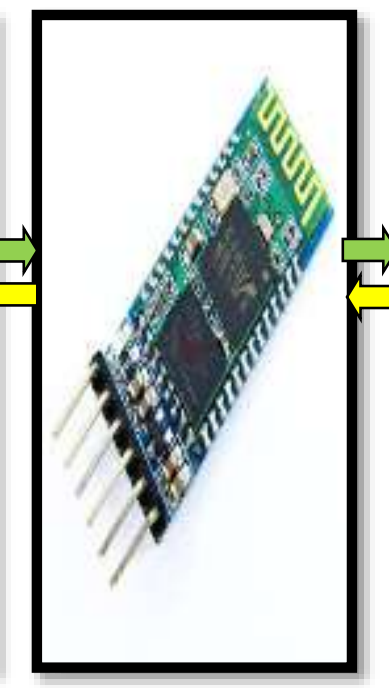

Bluetooth lengan bantu

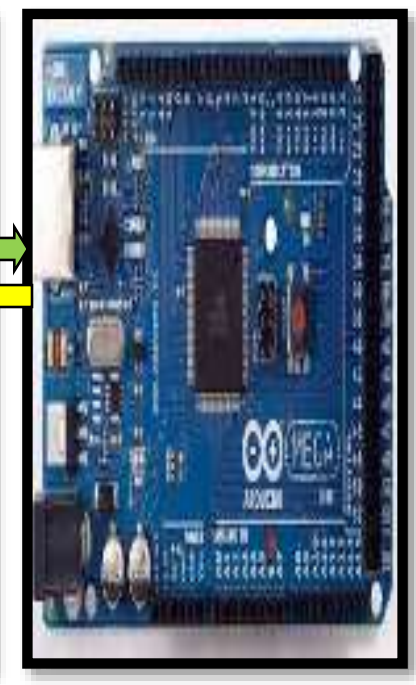

Mikrokontroller arduino

Gambar 4. Komunikasi aplikasi dan arduino

Aplikasi lengan bantu mengolah data voice command menjadi data serial, kemudian dikirim melalui jaringan nirkabel via bluetooth. Selain itu aplikasi lengan bantu juga berfungsi untuk menerima data berupa skala kekuatan otot dalam bentuk data serial. Kemudian diterjemahkan dan ditampilkan dalam aplikasi. Bluetooth berfungsi sebagai Receiver dan Transmiter, bertindak sebagai jembatan penghubung antara smartphone dengan arduino[5].Baudrate yang digunakan adalah 115200, yang bertujuan agar komunikasi dapat berjalan dengan cepat. Arduino merupakan mikrokontroller pengolah data [6]. Arduino menerima data dari smartphone, kemudian data tersebut diolah menjadi suatu proses. Setelah itu data dikirim kembali pada smartphone.

\subsection{Aplikasi Lengan Bantu}

Aplikasi ini merupakan media untuk mengucapkan perintah suara untuk mengendalikan lengan bantu. Aplikasi ini dibuat pada laman appinventor.mit.edu, sebuah situs untuk membuat aplikasi untuk smartphone android [7]. Gambar 5 menunjukkan aplikasi lengan bantu. 


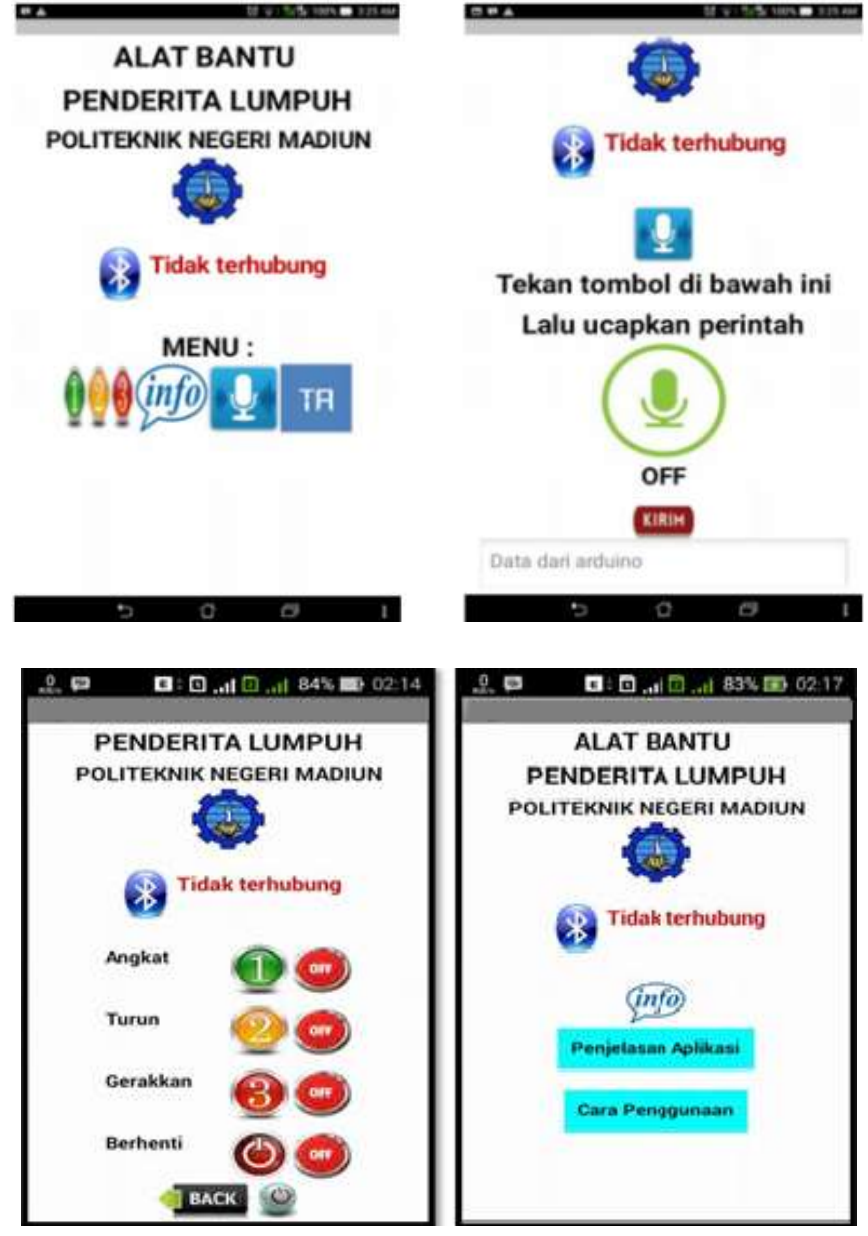

Gambar 5. Aplikasi lengan bantu

Aplikasi ini merupakan media untuk mengendalikan pergerakan dari lengan bantu. Aplikasi ini memiliki tiga menu, yaitu: pertama menu push button, diinisialisasikan sebagai perintah suara apabila menu utama perintah suara tidak dapat digunakan. Selanjutnya menu info, berisi keterangan informasi tentang alat dan cara penggunaan. Yang ketiga menu voice command, merupakan menu utama untuk menggerakkan lengan bantu, dan untuk mengetahui nilai skala kekuatan otot.

\subsection{Perancangan Sistem}

Gambar 6 menunjukkan diagram blok dari sistem.Voice command, untuk mengontrol pergerakan lengan.Button, diinisialisasikan sebagai pengganti fungsi voice command.Sensor MPX5050DP, penghitung skala kekuatan otot berdasarkan kontraksi otot.Sensor limit switch, sebagai pembatas pergerakkan lengan apabila terjadi error.Sensor rotary encoder, sebagai pembaca posisi sudut dari lengan bantu. Posisi sudut mengacu pada fisioterapi kelumpuhan.

Arduino merupakan pengolah utama dalam sistem ini. Didalam board arduino terdapat listing progam yang digunakan untuk menjalankan sistem secara keseluruhan, yaitu : progam untuk menerjemahkan perintah suara dari smartphone, progam menghitung skala kekuatan otot, dan progam pengendalian motor untuk pergerakan lengan.

LCD Display, menampilkam proses yang berjalan pada sistem: nilai tekanan udara pada manset, nilai skala kekuatan otot, nilai PWM, voice command yang diucapkan, dan nilai sudut lengan bantu.Motor power window, merupakan aktuator utama lengan bantu. Menggunakan driver L298N dan PWM untuk mengatur pergerakan berdasarkan perintah suara.Motor pompa udara, berfungsi untuk mengisi udara pada manset hingga tekanan udara 2,5kPa.Smartphone, 
untuk menampilkan nilai tekanan udara pada manset dan skala kekuatan otot berdasarkan perintah "skala".

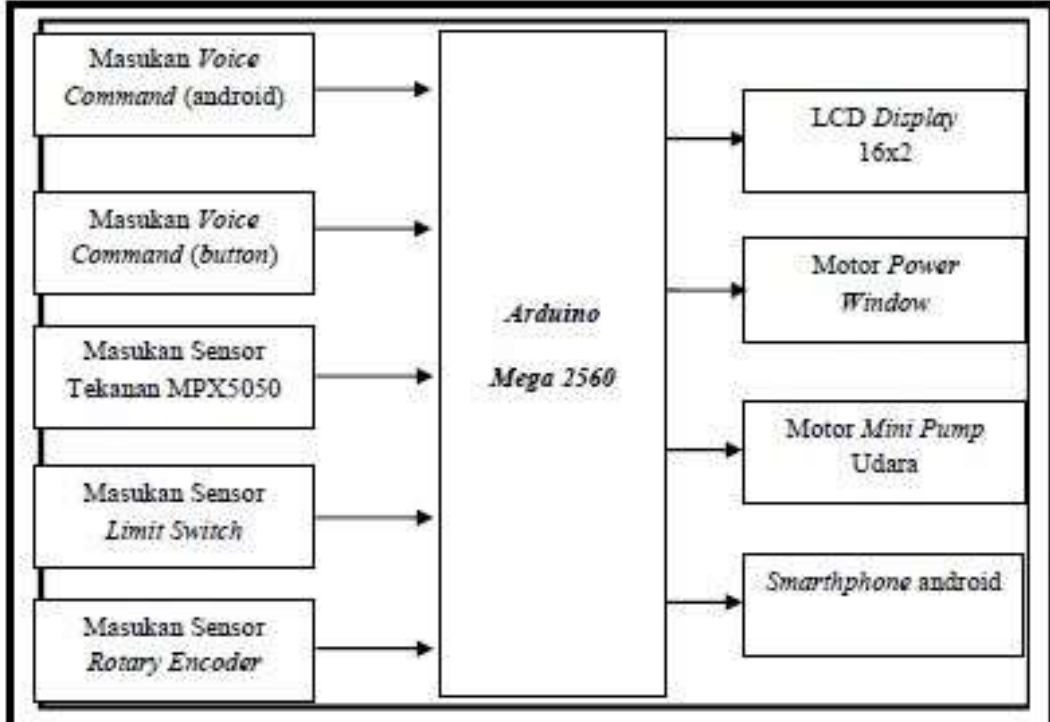

Gambar 6. Diagram blok sistem

\subsection{Perancangan Perangkat Keras}

Lengan bantu ini memiliki ukuran panjang $45 \mathrm{~cm}$ dan lebar maksimal $10 \mathrm{~cm}$, lebar dari lengan bantu ini dapat dikurangi berdasarkan ukuran dari lengan pengguna. Gambar 7 menunjukkan desain lengan bantu dan gambar 8 menunjukan hasil alat lengan bantu yang telah dibuat.

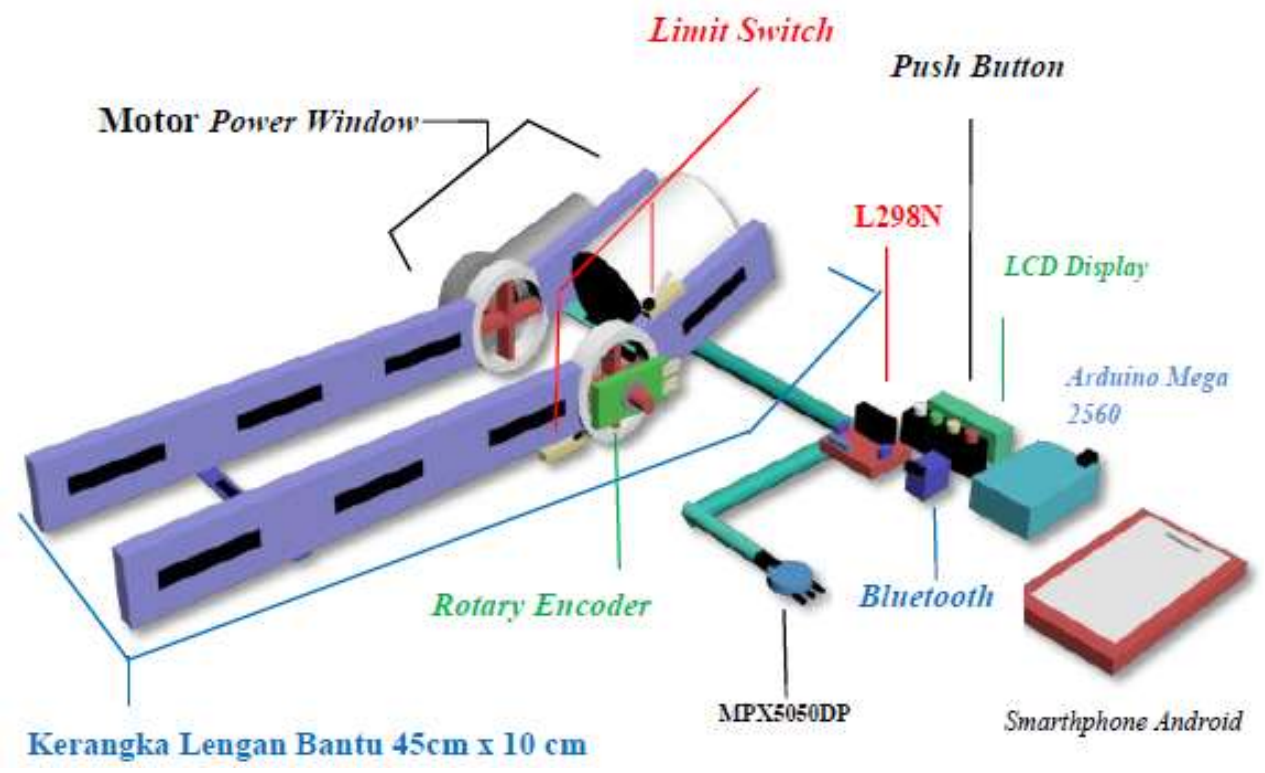

Gambar 7. Lengan bantu 


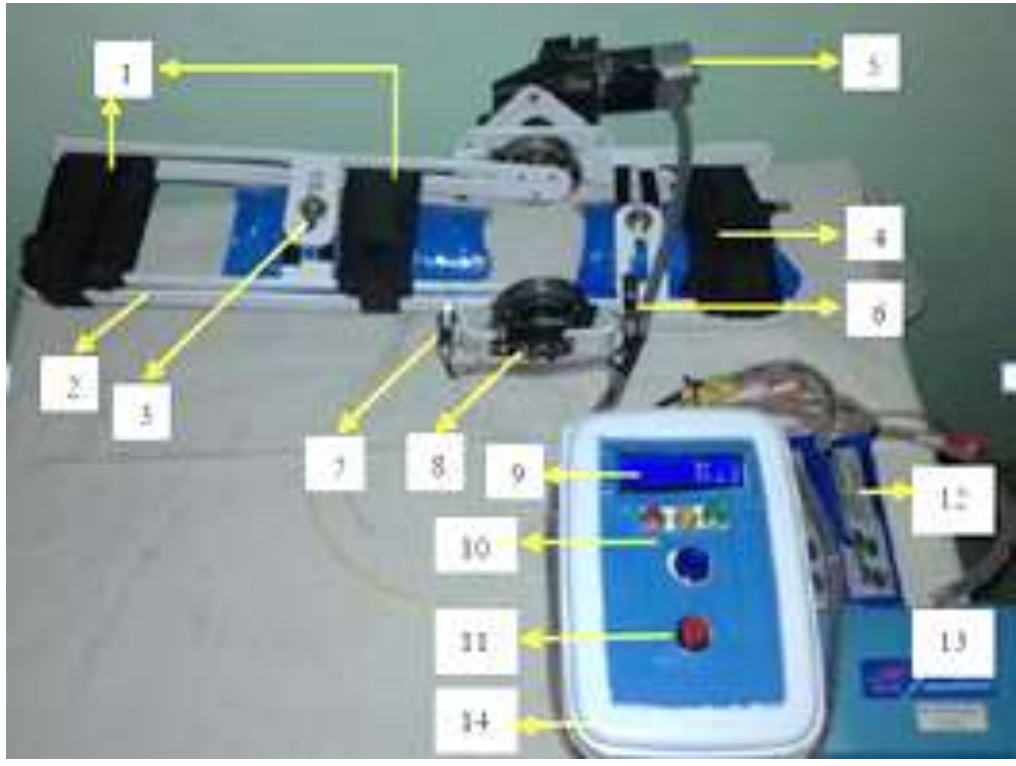

Gambar 8. Implementasi lengan bantu

Keterangan :

1. Sabuk pengaman, untuk mengencangkan lengan pengguna pada lengan bantu.

2. Kerangka utama lengan bantu.

3. Baut peregangan, untuk mengecilkan atau memperbesar lebar lengan bantu.

4. Manset, untuk media pengukuran skala otot.

5. Motorpower window, aktuator penggerak.

6. Limit switch A, pembatas gerakan angkat.

7. Limit switch $\mathrm{B}$, pembatas herakan turun.

8. Rotary encoder, sensor posisi sudut.

9. LCD Display.

10. Push button.

11. Tombol power on/off.

12. Batery lithium polymer $12 \mathrm{~V}$.

13. Motor pompa udara.

14. Box mikrokontroller, berisi board arduino, driver L298N, bluetooth, dan rangkaian hardware

\section{Hasil dan Pembahasan}

\subsection{Pengujian Perhitungan Skala Kekuatan Otot}

Skala kekuatan otot diukur menggunakan sensor MPX5050DP, sensor ini menghitung nilai tekanan udara pada manset yang dipasangkan pada lengan pengguna. Kontraksi dari otot bisep dan trisep akan menghasilkan tekanan udara yang akan mempengaruhi nilai keluaran sensor yang kemudian dikonversikan menjadi skala kekuatan otot.Persamaan rumus yang digunakan untuk mengubah tekanan udara menjadi nilai keluaran berupa voltase adalah sebagai berikut.

\section{Nominal Transfer Value :}

$$
\begin{aligned}
& \mathrm{V}_{\text {out }}=\mathrm{Vs}(\mathrm{Px} 0,018+0,04) \\
& \mathrm{V}_{\mathrm{s}}=5,0 \mathrm{~V} \pm 0,25 \mathrm{Vdc}
\end{aligned}
$$

Dimana: $\mathrm{V}_{\text {out }}=$ Keluaran sensor $(\mathrm{V})$

$\mathrm{V}_{\mathrm{s}} \quad=$ Tegangansupply $(5 \mathrm{~V})$

$\mathrm{P} \quad=$ Tekanan $(\mathrm{kPa})$

$0,018+0,04=$ Nilai kalibrasi tekanan atmosfer udara 
Berdasarkan persamaan (1)-(2), maka dapat diketahui nilai tekanan udara berdasarkan nilai keluaran sensor MPX5050DP [8]. Tabel 5 menunjukkan nilai keluaran MPX5050DP dengan nilai tekanan MPX5050DP dan tekanan teori untuk mencari nilai error. Nilai error dari sensor MPX masih dalam batas range toleransi maksimal, yaitu 2,5\% (+0,125 atau -0,125).

Tabel 6. Nilai keluaran MPX berbanding nilai tekanan.

\begin{tabular}{cccc}
\hline $\begin{array}{c}\text { Tegangan } \\
\text { MPX }\end{array}$ & $\begin{array}{c}\text { Tekanan } \\
\text { MPX }\end{array}$ & $\begin{array}{c}\text { Tekanan } \\
\text { Teori }\end{array}$ & $\begin{array}{c}\text { Error } \\
\mathbf{\pm 2 . 5 \%}\end{array}$ \\
\hline $1.00 \mathrm{~V}$ & $1.12 \mathrm{kPa}$ & $1.1 \mathrm{kPa}$ & 0.02 \\
\hline $2.00 \mathrm{~V}$ & $2.02 \mathrm{kPa}$ & $2 \mathrm{kPa}$ & 0.02 \\
\hline $3.00 \mathrm{~V}$ & $2.93 \mathrm{kPa}$ & $2.9 \mathrm{kPa}$ & 0.03 \\
\hline $4.00 \mathrm{~V}$ & $3.89 \mathrm{kPa}$ & $3.8 \mathrm{kPa}$ & 0.09 \\
\hline $4.70 \mathrm{~V}$ & $4.68 \mathrm{kPa}$ & $4.7 \mathrm{kPa}$ & -0.02 \\
\hline
\end{tabular}

\subsection{Pengujian Pergerakan Lengan}

Pengujian pergerakan ini dilakukan selama dua hari, pada pagi dan sore hari. Pengujian dilakukan pada orang normal dan penderita lumpuh. Pengujian bertujuan untuk mengetahui nilai skala kekuatan otot setelah menggunakan lengan bantu oleh pengguna. Gambar 9 menunjukkan pergerakan lengan bantu saat perintah angkat pada orang normal.

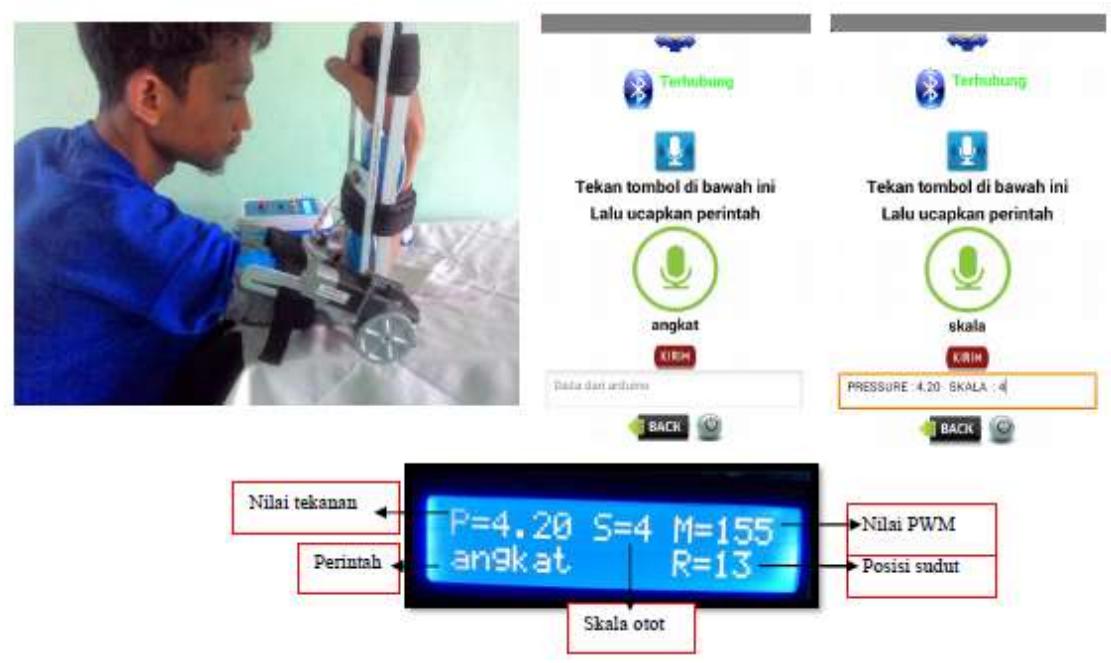

Gambar 9. Pengujian pergerakan lengan bantu saat perintah angkat pada orang normal

Pengujian dilakukan selama dua hari, nilai rata-rata kekuatan otot pada orang normal yang telah dilakukan ditunjukkan pada tabel 6 . Tabel 7 menunjukkan rata-rata hasil pengujian pada orang normal. Gambar 10 menunjukkan grafik hasil rata-rata pengujian pada orang normal. 

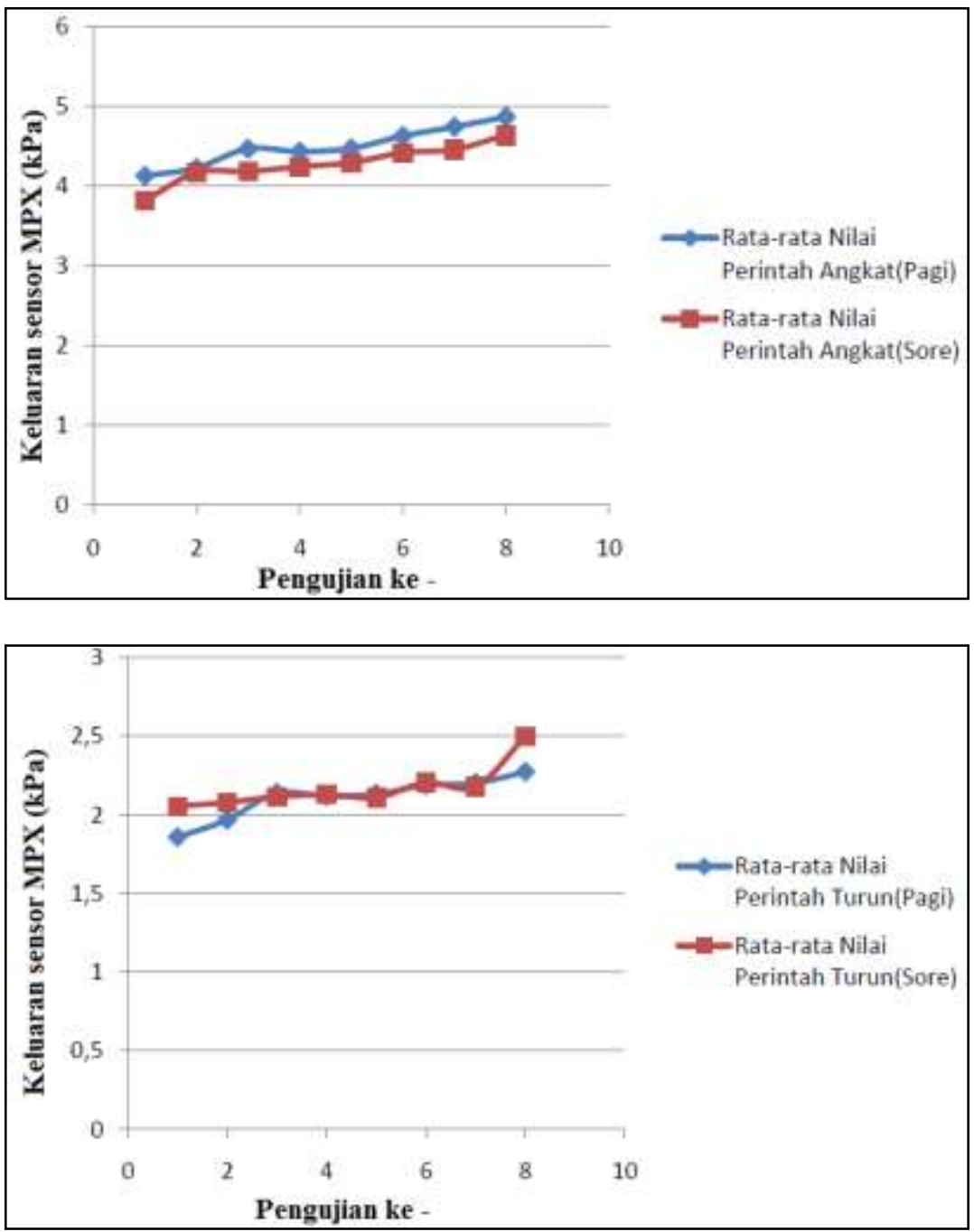

Gambar 10.Grafik rata-rata kekuatan otot pada orang normal

Tabel 7. Hasil rata-rata pengujian orang normal

\begin{tabular}{cccccccccc}
\hline \multirow{2}{*}{$\begin{array}{c}\text { Pengujian } \\
\text { ke }-\end{array}$} & \multicolumn{4}{c}{ Angkat } & \multicolumn{2}{c}{ Turun } & \multicolumn{3}{c}{ Angkat } \\
\cline { 2 - 10 } & $\begin{array}{c}\text { Tekanan } \\
(\mathbf{k P a})\end{array}$ & Skala & $\begin{array}{c}\text { Tekanan } \\
\mathbf{( k P a )}\end{array}$ & Skala & $\begin{array}{c}\text { Tekanan } \\
(\mathbf{k P a})\end{array}$ & Skala & $\begin{array}{c}\text { Tekanan } \\
(\mathbf{k P a})\end{array}$ & Skala \\
\hline 1 & 4.13 & 5 & 1.86 & 2 & 3.82 & 4 & 2.05 & 3 \\
\hline 2 & 4.23 & 5 & 1.97 & 2 & 4.17 & 5 & 2.08 & 3 \\
\hline 3 & 4.47 & 5 & 2.14 & 3 & 4.18 & 5 & 2.11 & 3 \\
\hline 4 & 4.43 & 5 & 2.12 & 3 & 4.24 & 5 & 2.13 & 3 \\
\hline 5 & 4.47 & 5 & 2.13 & 3 & 4.29 & 5 & 2.11 & 3 \\
\hline 6 & 4.63 & 5 & 2.19 & 3 & 4.42 & 5 & 2.20 & 3 \\
\hline 7 & 4.75 & 5 & 2.20 & 3 & 4.46 & 5 & 2.18 & 3 \\
\hline 8 & 4.87 & 5 & 2.27 & 3 & 4.64 & 5 & 2.5 & 3 \\
\hline
\end{tabular}

Dari pengujian yang telah dilakukan selama dua hari pada orang normal, dapat diketahui bahwa penggunaan alat ini menurunkan skala kekuatan otot oleh pengguna orang normal. Hal tersebut dikarenakan penggunaan dari alat ini dapat menyebabkan kelelahan otot (seperti orang berolahraga) yang menyebabkan pengguna mengalami penuruman kekuatan otot.

Pengujian pada penderita lumpuh dilakukan selama dua hari, yaitu pada pagi dan sore hari. Penderita lumpuh yang dilakukan pengujian mengalami lumpuh kekuan sendi tangan. Gambar 11 menunjukkan pergerakan lengan bantu saat perintah angkat pada penderita lumpuh. 

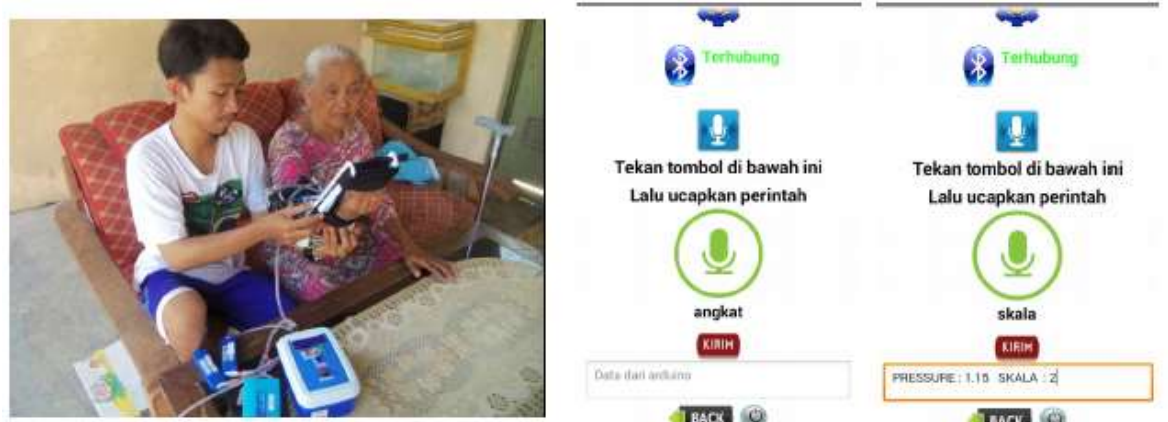

Tekan tombol di bawah in

Lalu ucapkan perintah
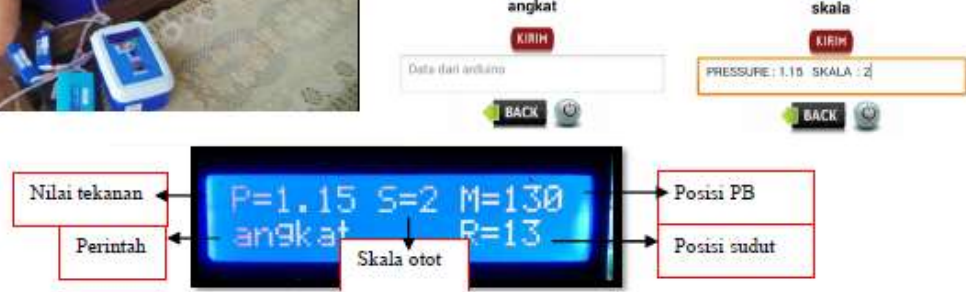

Gambar 11. Pengujian pergerakan lengan bantu saat perintah angkat pada penderita lumpuh

Pengujian dilakukan selama dua hari, nilai rata-rata kekuatan otot pada penderita lumpuh ditunjukkan pada Tabel 8. Gambar 12 menunjukkan grafik hasil rata-rata pengujian penderita lumpuh.
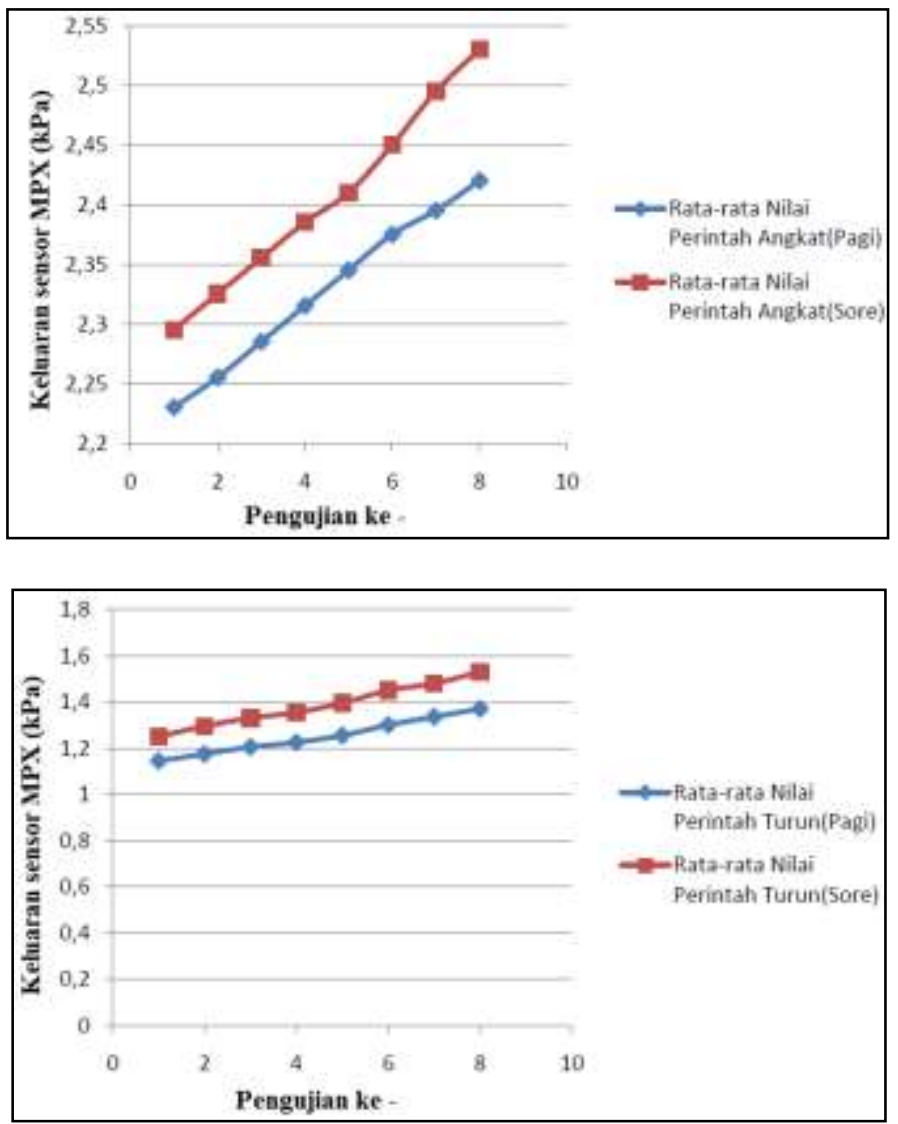

Gambar 12. Grafik rata-rata kekuatan otot pada penderita lumpuh 
Tabel 8. Hasil rata-rata pengujian penderita lumpuh

\begin{tabular}{|c|c|c|c|c|c|c|c|c|}
\hline \multirow{3}{*}{$\begin{array}{c}\text { Pengujian } \\
\text { ke - }\end{array}$} & \multicolumn{4}{|c|}{ Pagi hari } & \multicolumn{4}{|c|}{ Sore hari } \\
\hline & \multicolumn{2}{|c|}{ Angkat } & \multicolumn{2}{|c|}{ Turun } & \multicolumn{2}{|c|}{ Angkat } & \multicolumn{2}{|c|}{ Turun } \\
\hline & $\begin{array}{c}\text { Tekanan } \\
\text { (kPa) }\end{array}$ & Skala & $\begin{array}{c}\text { Tekanan } \\
\text { (kPa) }\end{array}$ & Skala & $\begin{array}{c}\text { Tekanan } \\
\text { (kPa) }\end{array}$ & Skala & $\begin{array}{c}\text { Tekanan } \\
\text { (kPa) }\end{array}$ & Skala \\
\hline 1 & 2.23 & 2 & 1.14 & 1 & 2.29 & 2 & 1.25 & 1 \\
\hline 2 & 2.25 & 2 & 1.17 & 1 & 2.32 & 2 & 1.29 & 1 \\
\hline 3 & 2.28 & 2 & 1.20 & 1 & 2.35 & 2 & 1.33 & 1 \\
\hline 4 & 2.31 & 2 & 1.22 & 1 & 2.38 & 2 & 1.35 & 1 \\
\hline 5 & 2.34 & 2 & 1.25 & 1 & 2.41 & 2 & 1.39 & 1 \\
\hline 6 & 2.37 & 2 & 1.25 & 1 & 2.45 & 2 & 1.45 & 1 \\
\hline 7 & 2.39 & 2 & 1.3 & 1 & 2.49 & 2 & 1.48 & 1 \\
\hline 8 & 2.42 & 2 & 1.37 & 1 & 2.53 & 2 & 1.53 & 1 \\
\hline
\end{tabular}

Dari pengujian yang telah dilakukan, dapat diketahui bahwa grafik kekuatan otot pada penderita lumpuh mengalami peningkatan. Peningkatan skala kekuatan otot tersebut terjadi karena pergerakan lengan bantu memicu otot bisep dan juga trisep mengalami kontraksi, sehingga terangsang untuk mengikuti pergerakan lengan bantu. Hal ini diharapkan dapat memulihkan kondisi fisik pasien pengguna seoptimal mungkin.

\section{Kesimpulan}

Alat bantu penggerak lengan menggunakan perintah suara untuk mengontrol pergerakan dari lengan. Pergerakan dari lengan adalah angkat (sudut $130^{\circ}$ ), turun (sudut $30^{\circ}$ ), gerakkan dan skala.Perhitungan skala kekuatan otot menggunakan sensor MPX5050DP. Sensor mengukur kekuatan otot berdasarkan kontraksi dari otot bisep dan trisep yang akan mempengaruhi tekanan udara.Penggunaan dari alat ini pada orang normal menimbulkan skala kekuatan otot yang cenderung menurun. Hal tersebut dikarenakan penggunaan yang menimbulkan kelelahan otot. Sedangkan penggunaan pada penderita lumpuh mampu menghasilkan rata-rata kekuatan otot yang naik.

\section{Daftar Pustaka}

[1]. Kelly, M. Goedert. Stroke Rehabilitation Researchers Report Improvement in Spatial Neglect with Prism. Neurorehabilitation and Neural Repair. December, 2013

[2]. P, Diane. Robot Terapi untuk Penderita Stroke.Jevuska. April 2010

[3]. Andras, Toth. Robots with Patients. ABB Review. 2006

[4]. GobarFazakus, Monika Horvath, FiborTroznai. Robot-Mediated Upper Limb Physiotherapy for Patients with Spastic Hemiparesis: A Preliminary Study. J. Rehabil Med. 2007 pp. 580582.

[5]. Yulianto, Dhoni. Rancang Bangun Sistem Kontrol Otomatis pada Alat Bantu Gerak Physio Therapy Lengan Bawah.Skripsi. 2007.

[6]. R. Richardson. Design and Control of a Three Degree of Freedom Pneumatic Physio Therapy Robot.Robotica Volume 21. December 2003. Pp. 589-604

[7]. Tandika, Keven. Aplikasi Voice Recognition Berbasis Android denganMenggunakanBahasa Indonesia.Skripsi.Universitas Kristen Maranatha Bandung. 2014

[8]. Adiluhung, Johan. Alat Pengukur Tekanan Darah Otomatis Berbasis Mikrokontroler Untuk Pasien Rawat Jalan dengan SMS Gateway. Surabaya : Politeknik Elektronika Negeri Surabaya. 2013. 